\title{
LIFE CYCLE OF A MILITARY PRODUCT
}

\author{
Nicolae MORO \\ moro.nicu@armyacademy.ro \\ “NICOLAE B̆LLCESCU” LAND FOCES ACADEMY, SIBIU, ROMANIA
}

\begin{abstract}
Romania's membership of the select group of states belonging to the North Atlantic Treaty Organization brings, in addition to the expected security benefits and assurances and commitments and obligations that we have to assume. The participation of politicians, militaries and Romanian experts in the decision-making within the specialized committees of the NATO structures is an extremely important element for the assertion of Romania as a security guarantor in the area, a hypostasis that was only a vision a few years ago. This role of our country must be supported by strong and powerful military capabilities, capabilities that are hard to reach for many of the countries in Eastern Europe. The economically advantageous and technologically viable solution for a period of time is to acquire advanced military technical systems that are equipped with the great economic powers of NATO, systems used and verified by these armies, revitalized and upgraded, a second life goal.
\end{abstract}

\section{KEYWORDS:}

Lifecycle, lifetime, modernization, improvement, revitalization, efficiency, effectiveness, relaunch

\section{Introduction}

Military technical systems are a special category of material goods whose lifetime is characterized by a time of peace of a particular evolution compared to the category of civilian goods of general use. This particular evolution of the life cycle is determined by the special characteristics of these products, their extremely high price and their social utility. This "repeatability" of the life cycle to another beneficiary is primarily related to their need to cover the security needs that these revitalized technical systems can provide under an economically-financial advantageous balance. These "spiral" lifecycles of military-oriented products are a variant that some producers of reputable material goods have assimilated (from the luxury automotive industry) with excellent results from an economic point of view as much as possible chosen for marketing reasons. Although at first glance this approach does not seem to be a very advantageous one, the short and medium term can be a quick and beneficial solution for the second user who can benefit from the capabilities of a reliable and verified technical system but especially upgraded to the current level of global performance. This solution is perfectly suited to countries with medium economic power but with major security needs required by NATO membership but also to the complex geopolitical situation of the moment. 


\section{The concept of a Product's Life Cycle \\ Product Life Cycle (PFC) refers to the} average life span of a product and represents the amount of time the product / brand of the product is on the market, starting with the introduction and ending with the withdrawal (these two phases can be identified with ease). However, the most exact definition is given by the SR EN ISO 14040: 2002 standard where it is stated that the life cycle of a product is represented by "consecutive and interconnected phases of a product system, from raw material acquisition or generation of resources to post-use". For a more accurate understanding of the concept, many authors are analogous to biology, where the products are born, grow, mature and then grow older and die.

In according with Rey, Martín-Gil \& Velasco (2004), there are 2 major concepts about the life cycle of a product. The first one (more widespread) claim that a product has 4 stages of the life cycle:

1. release;

2. the growth;

3. maturity;

4. decline.

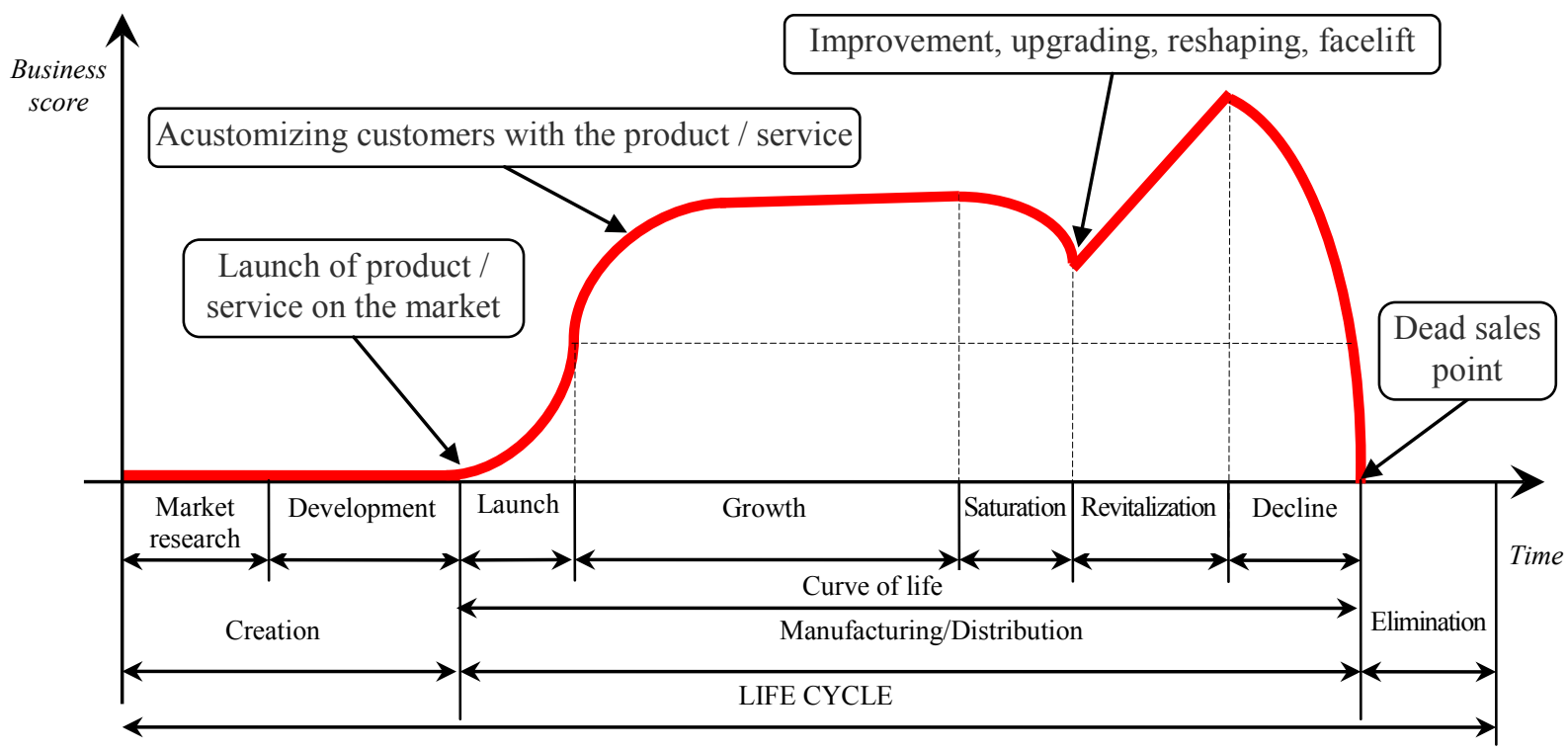

Figure no. 1 Life cycle phases of the product (adaptation after Westkämper)

At the launch stage, the organization's main goal is to inform customers of the emergence of the new product. Spending at this stage is high, low sales and negligible, even negative, profits. The product is presented in one, at most two constructive variants, and the distribution, especially for expensive products, is limited, selective.

The growth stage is characterized by rapid growth in sales and profit, the manufacturer aims to maximize its market share and create a strong brand. Consumers are numerous but many competitors and imitators also appear. The manufacturer has to diversify its range of products, expand its distribution and stimulate brand preference.
At the maturity stage sales volume stabilizes. The manufacturer tries to maintain its competitive advantage by improving product features, extending warranty and after-sales service, and price reductions. There is mass consumption, but competition is at the highest level. Promoting is very intense and competitive.

In the decline phase, sales decline as other substitutes appear on the market, or consumer interest in the product is reduced. The manufacturer checks that there are still opportunities to make a profit and watches the optimal time to abandon the product. The product line is restricted to the most wanted models, distribution becomes 
selective again and promotional actions are limited to product reminders. For some products, the facelift is adopted, which is basically a cosmetic product to attract demanding or indecisive customers (especially for automotive products). Companies often aim at creating a balanced product portfolio with products at different stages of the life cycle, in order to eliminate the shortcomings of each phase in order to compensate for possible losses with the profits of other products.

In line with the work of Westkämper, E. (2000), the second conception (Figure no. 1) states that a product has 6 stages of the life cycle:

1. market research;

2. research, design, development;

3. launch / marketing;

4. growth;

5. saturation (maturity);

6. decline and disappearance from the market.
There is a close link between the sales volume and expenditure and profit curves in all 6 phases of the product lifecycle. Expenditures are very high in the R\&D phase and in the rebound phase, spending is lower in growth and maturity, and there is no profit at the design and launch stage, increasing slightly from the growth and maturity stage and declining during the decline.

\section{The military approach to the life-cycle concept of a product}

Analyzing the evolution of the lifecycle of military-oriented products (especially heavy armaments, armor or combat planes), there can be noticed that there are differences with civilian products because most military products still have a the last important step, namely relaunching (with or without improvement or modernization). So for these products there is a staging that looks like this (Figure no. 2).

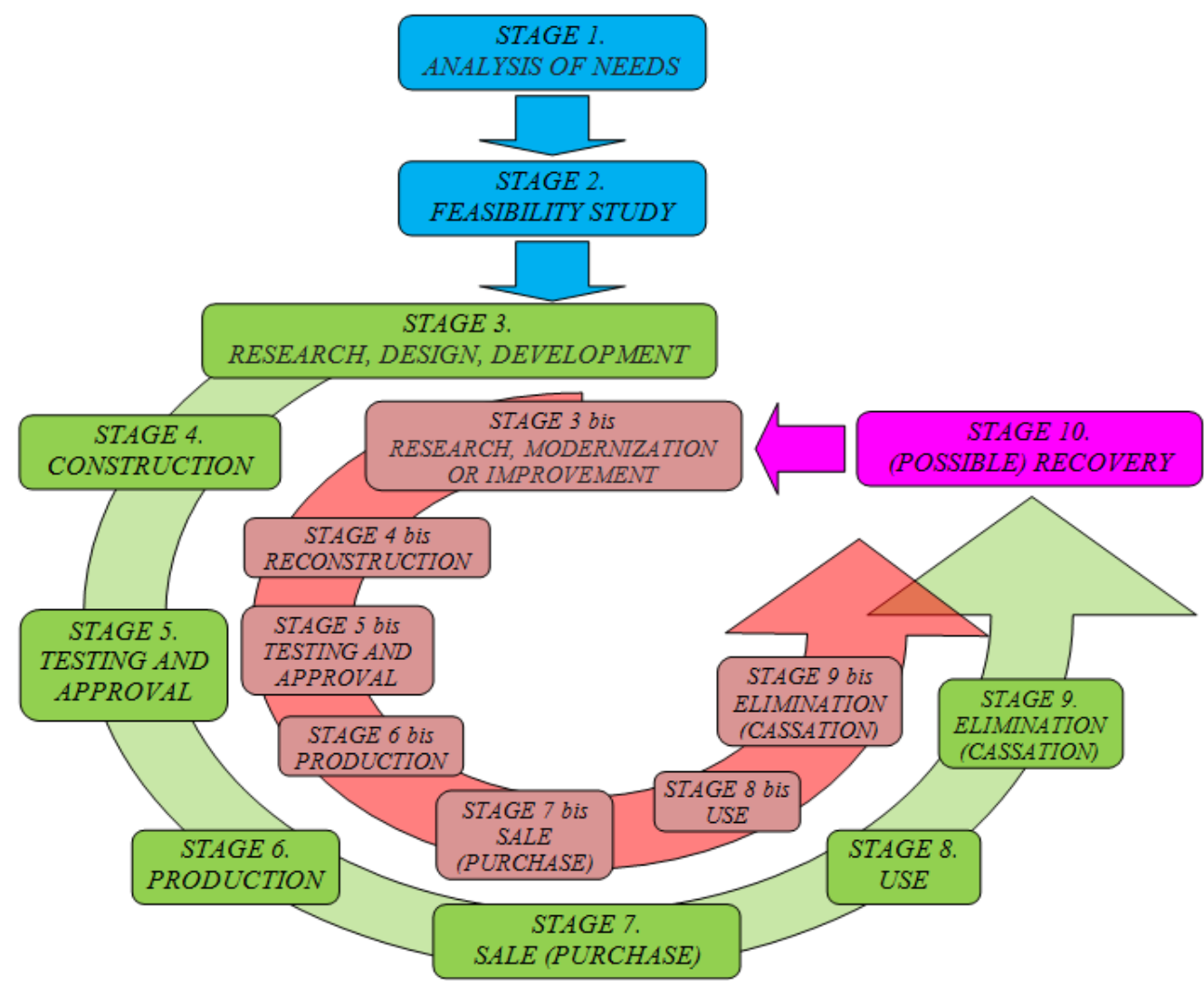

Figure no. 2 Life cycle stages of a military product 
Here are some explanations for this approach. The emergence of the last stage of "re-launching" occurs when this product is considered morally or physically used for a particular user, the product is discontinued for that user, but a potential buyer appears who, due to a particular circumstance, is interested in acquiring that obvious military technical system at a lower but affordable price (as is the case with the Romanian frigates King Ferdinand and Queen Mary). By virtue of purchase and modernization contracts concluded between the parties, that technical system is revitalized, upgraded / adapted to the needs of the customer and then delivered to him as a new product with regard to the contract (warranty and postwarranty service, further improvements, etc.).

The American view of integrated logistics support for military technical systems, as set out in the Support Operations Handbook, claims that the life-cycle stages of special-purpose products are as follows:

1. the definition phase (examination of the concept);

2. demonstration - validation stage;

3 . the design and testing stage;

4. the production and deployment phase;

5. operation (operation) and support (maintenance) stage;

6. phase-out stage

A detailed approach to this lifecycle of military goods is presented by Siteanu, E., (2005) who enumerated fifteen stages:

1. analyzing (determining) the necessity of manufacturing a technical product, determining the destination, formulating the functions and establishing the requirements (specification);

2. definition of the technical product and functional analysis, establishment of the criteria and resources of research, design and development;

3. analysis of probable variants, possible realizations and choosing the optimal ones;

4. preliminary design;

5. design documentation design;
6. detailed design of the product;

7. manufacture of the prototype (functional model);

8. prototype testing and its assessment;

9. preparation of the manufacturing;

10. realization of the zero series, experimentation under the required conditions and approval;

11. serial production and delivery to the beneficiaries;

12. the exploitation of the products to the beneficiaries and the maintenance activities;

13. performing improvement (modernization) activities;

14. removal from service;

15. revitalization (optional).

Another approach to the concept of lifecycle concerns the concept of the life of a product that includes the production cycle + the duration of use in consumption (when we have durable goods). The production cycle and the duration of use of a product may be influenced by certain factors (technical progress, increased revenue, etc.) that increase the life cycle.

Duration of use is assimilated in the Romanian military terminology with the physical life of the technical system which differs from the useful life which is always lower. Physical lifetime also includes periods of time that the technical system is in store or in conservation, so that the system is not actually used. Useful life is the amount of time over which the asset subject to depreciation is expected to be used.

The stage that is the subject of the paper is the use (operational or operational) phase, ie the lifetime that lasts for the longest time. It may range from a few days, weeks or months (ammunition, consumables or explosives) up to several decades (light or heavy weapons, armored vehicles, transport vehicles, planes or ships). For the latter, the issue of quality in service is very serious, because the lack of this quality can 
shorten the service life under the rules established by the legislation in force.

Practically, the service life starts from the moment when the military technical system leaves the manufacturer's gate and is completed by disassembly (demilitarization, neutralization or rehabilitation) under the conditions set by the normative. Due to the very high costs, its operational importance and the effects produced, the intact maintenance of the quality characteristics of these special purpose products is very important. The detail of this step is illustrated in Figure no. 3.

In the military system, special attention is paid to the operational classification of military technical systems to assess which ones are operational (in the resource) and which are unavailable (unfit for use for a period of time).

In the life cycle of a military technical system (for example an artillery piece), it may alter the operating and non-operational periods, depending on a series of graphical factors presented in Figure no. 3. According to the presented graphical situation, the situation of the military technical systems depends mainly on:

- qualification of the personnel who maintains, exploits or repairs it;

- how it is used;

- the way in which maintenance interventions are planned and executed;

- technical construction solution and materials used in manufacturing;

- hidden vices of materials that were not detected during manufacture.

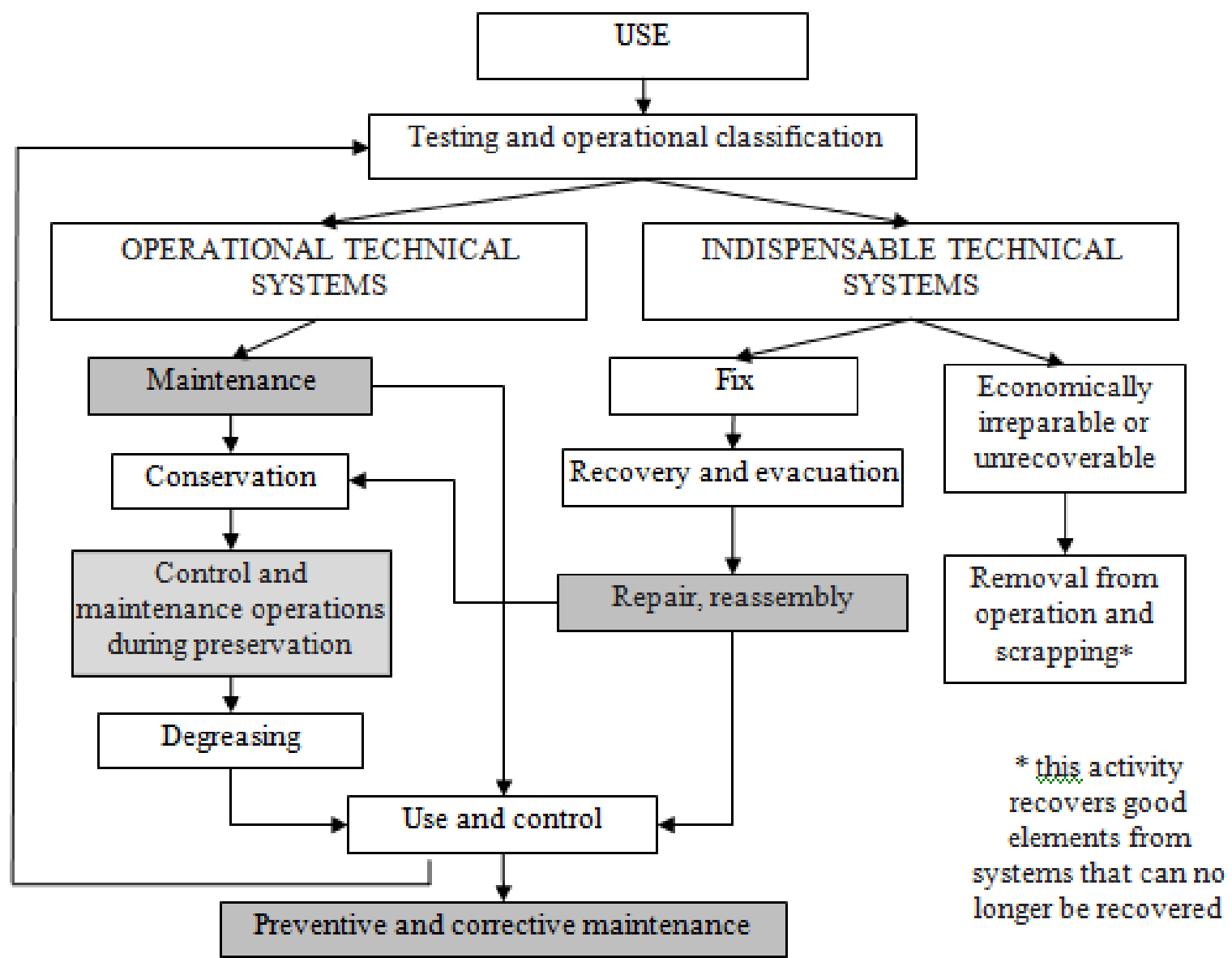

Figure no. 3 Details of the use of a military technical system 
As far as the human factor is concerned, the technical resource can be maintained within the limits assessed by design through training and specialization of the personnel on the line of knowledge, exploitation, maintenance, diagnosis and repair of technical systems. The possibility of increasing the duration of use arises as a result of the intervention and application of one or more of the factors presented in
Figure no. 4 on subassemblies and benchmarks in the composition of a technical system. Intervention is actually improving the technical parameters of the sub-assemblies referred to. In this way, under normal use conditions, the duration of the weapon operation increases without the risk of incidents (especially during firing).

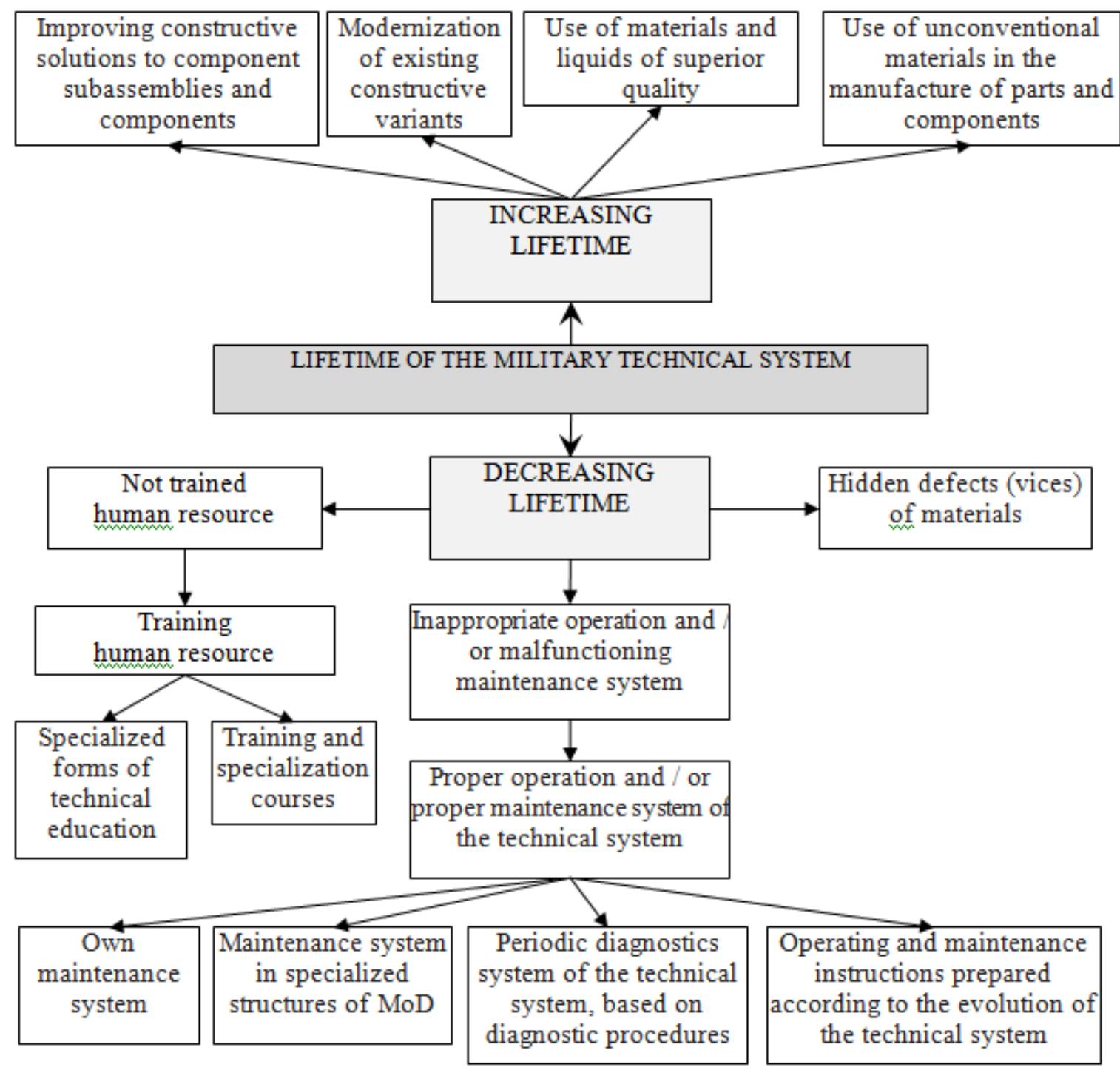

Figure no. 4 Factors that influence the life of a technical system 


\section{Case study on the evolution of the life cycle of military engineering systems acquired by the romanian army}

\subsection{The life cycle of class 22 frigates}

King Ferdinand (F-221) is a Class 22 frigate (also called Broadsword) and is the current flagship of the Romanian Military Navy. Prior to being sold to Romania, HMS Coventry (F-98 number) belonged to the Royal Navy. Shipbuilding operations began in Swan Hunter's docks in 1984, staffed two years later in 1986. It was fully equipped with weapons and technical equipment until 1988 becoming fully operational a year later. He left Royal Navy on January 17, 2002, at the time he navigated $348,372 \mathrm{Mm}$, being permanently and effectively employed in the Royal Navy combat service, representing United Kingdom's contribution to NATO's Atlantic Navy, being deployed in various geographical areas on all the seas and oceans of the world. The actual navigation time exceeds 30,000 hours, meaning a rate of use at sea of more than $25 \%$ of the total operational duty time.

Queen Mary (F-222) is also a Class 22 frigate and before being sold to Romania, it was named HMS London (F-95), being the commander of the Royal Navy during The Gulf War of 1991. Shipbuilding began on February 7, 1983 at Yarrow Shipbuilders and was launched on October 27, 1984. It was fully equipped with weapons and techniques until June 5, 1987, and who left Royal Navy on 14 January 1999.

The ships were purchased from the United Kingdom by the Romanian state on 14 January 2003 and renamed King Ferdinand and Queen Mary respectively. The frigate King Ferdinand was taught to Romania on August 19, 2004, and the frigate Queen Mary on April 21, 2005 and were immediately subjected to evidence at sea. King Ferdinand was received by the Romanian Military Navy on 9 September 2004 and Queen Mary on July 25, 2005, when the frigates regeneration programs were started, a program that would ensure the initial parameters of the on-board technique and the implementation of new techniques and equipment. In this configuration, which will probably be upgraded over time, ships will provide the combat service in the Romanian Navy for a period of at least 25 years, as long as the service life is in line with the regulations in Romania Navy forces.

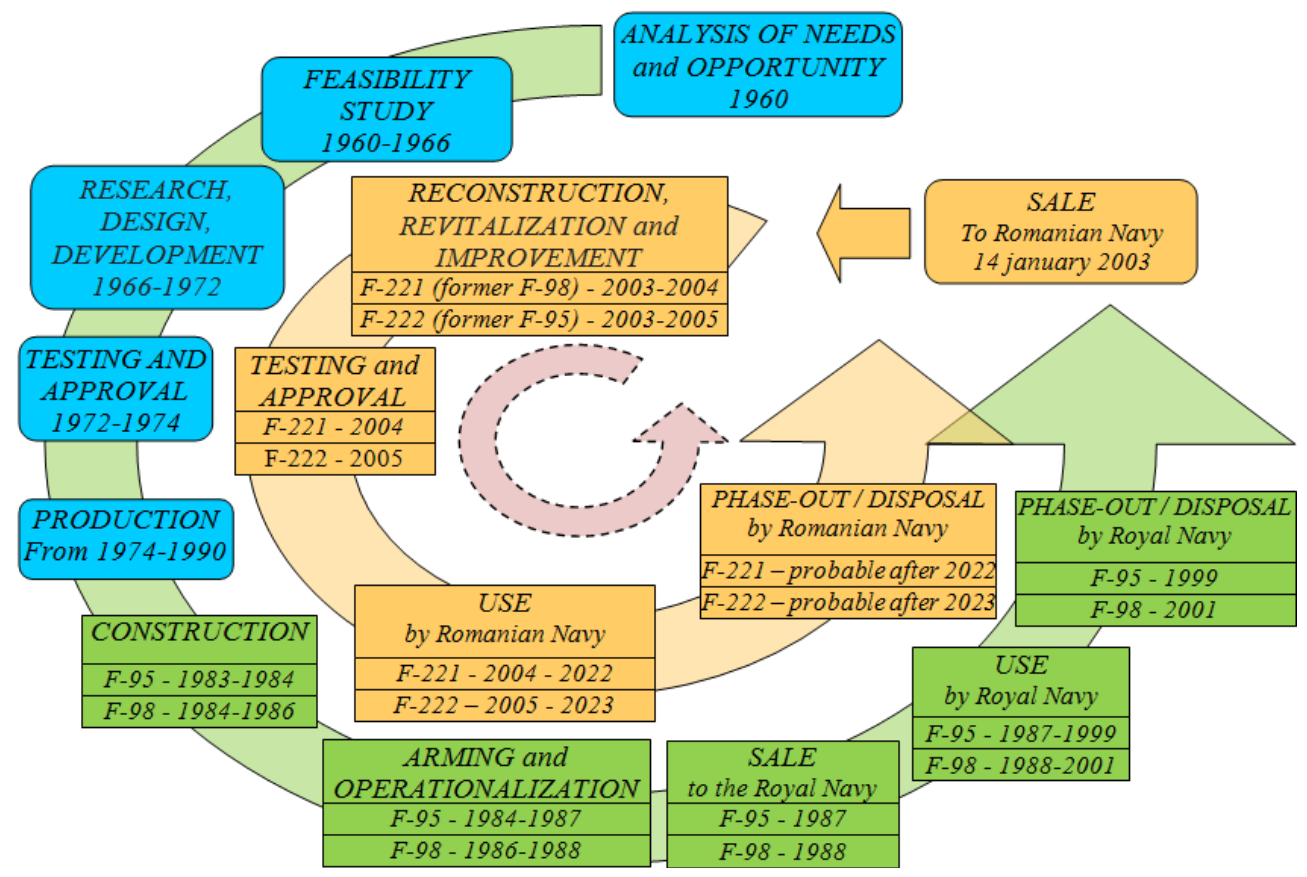

Figure no. 5 Life cycle stages of a Romanian frigates "F-221 King Ferdinand" and "F-222 Queen Maria" 


\subsection{The life cycle of F-16 aircrafts}

In 2013, Romania started the acquisition of multirole combat aircraft, for an agreement with the American and Portuguese Governments for a transfer of 12 F-16 aircraft from Portugal. Airplanes, although they are used, are only half their life, and some 8,000 hours of flight can be used. In addition, the devices have been updated with the latest technologies and software specifications available for the model.

According to Aviation Week \& Space Technology, the aforementioned F16 appliances were endowed with the Portuguese Air Force through the Atlantis I and Atlantis II Program, a compensation granted to Lisbon for the use of the US Air Base in the Azores. The agreement included the delivery of 20 F16 Block 15 planes plus spare parts, support and training equipment for maintenance and piloting teams. In 1996, the Portuguese Air Force requested another 25 F16 Aircraft Class A / B of the surplus US Air Force, along with five exchange engines, estimated costs was \$258 million.

In September 2016, the first six aircraft of this type entered the service of the Romanian Air Force. Of the 12 Block 15 aircraft purchased, 9 are the F-16As oneseat model and 3 are F-16Bs with two seats.
Airplanes, although from an older production, have meanwhile undergone a major upgrading - Mid-Life Upgrade (MLU) as they are told in official language - and the models that will fit into Romania are ready to interact with other planes which many NATO member states use.

The F-16 Airplanes of Romania updated through the Mid-Life upgrade have integrated a Sniper Advanced Targeting Pod system, new types of headphones for tracking and targeting, software upgrades and communications. The new type of helmet allows pilots to have information always in front of their eyes and can acquire a target even when it is behind the plane. The American company continues to build the F16, although it has been more than 38 years since the model was introduced into service.

The work required to update the F 16A/B Block 15 MLU M 5.2 models bought by Romania was occupied by Portugal, while Lockheed Martin's role as a manufacturer is to provide logistical and technological support, especially in the upcoming period when Romania will operate the aircraft.

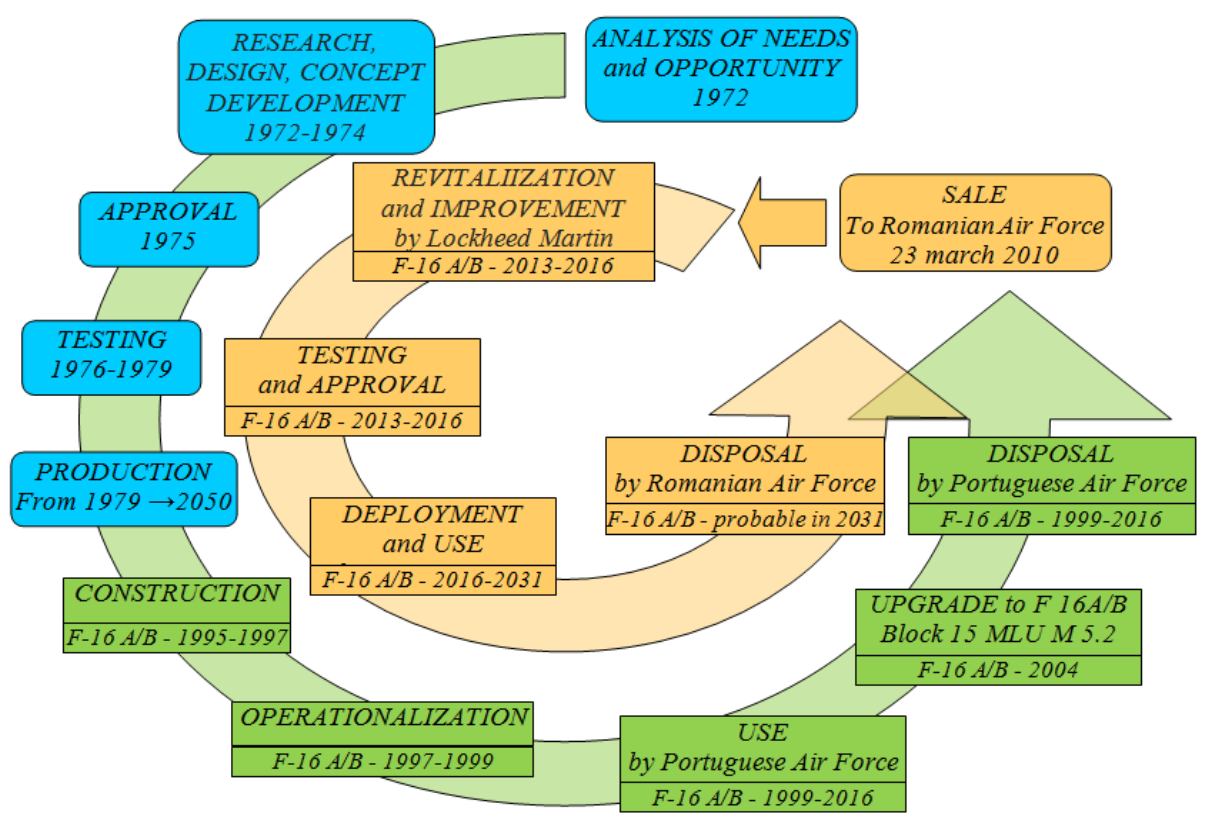

Figure no. 6 Life cycle stages of a Romanian F-16 aircrafts 


\section{Conclusions}

By summarizing the data from the literature, the observations made during the study, as well as the experience accumulated during almost three decades of active military service, the following conclusions can be drawn:

- the quality characteristics of military technical systems are generally the same as civil engineering systems but with specific features of military use;

- the quality characteristics of military technical systems must be maintained at the same parameters throughout their lifetime as they are often used in extreme conditions at their full capacity;

- the life cycle of military technical systems respects the structure of the life cycle of the material products, but there is a very widespread last stage, the relaunching (many of the foreign weapons systems acquired by Romania in the last decade are in this phase);

- the policy taken over the past years to acquire "second hand" technical systems (re-launched military technical systems from alliance partners, although it seems advantageous in the long run it will prove costly;

- most of the military technical systems in force (terrestrial, air and naval) have their useful life expired and maintenance of these technical systems in the current use is done with great expense, especially on the maintenance area;
- recently acquired new (modern and performing) technical systems represent a minor percentage relative to the entire existing fleet, and due to unfavorable economic aspects, the purchase of modern weapons and modern fighting techniques could be postponed for the moment (purchase implies imports of very expensive systems or subassemblies that are difficult to bear financially).

Research on the topic addressed has opened up opportunities for studying and investigating the phenomena and processes that take place during the use of these products for military purposes by:

- the development of the theoretical bases on indicators of availability, maintenance and reliability of the military technical systems and the development of a S.W.O.T. objectives of the current state of these systems;

- conducting research and analysis on the types of malfunctions identified in the military technical systems in operation and their interpretation;

- the study of the types of wear to which the military technical systems are subjected in the use phase with the analysis of the particular conditions of use;

- the analysis of the way of quality assurance at the stage of using the military technical systems.

\section{REFERENCES}

Rey, F.J., Martín-Gil, J., \& Velasco, E. (2004). Life Cycle Assessment and external environmental cost analysis of heat pumps. Environmental Engineering Science, vol. 21, 591.

Siteanu, E. (2005). Teoria mentenanţei. Bucureşti: Editura Universităţii Naţionale de Apărare, 120-121.

Westkämper, E. (2000). Live Cylce Management and Assessment. Approaches and Visions Towards Sustainable Manufacturing. Annals of the CIRP, Vol. 49/2, 501-522. 